\title{
ОСОБЕННОСТИ РЕИНЖИНИРИНГА БИЗНЕС-ПРОЦЕССОВ НА СОВРЕМЕННЫХ ПРЕАПРИЯТИЯХ
}

\begin{abstract}
Аннотауия. В данной статье рассматриваются аспекты реинжиниринга бизнес-проиессов, характерные черты реинжиниринга, преимущеетва и недостатки реинжиниринга бизнес-

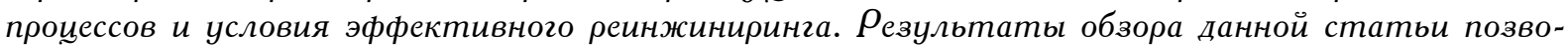
ляют понять, что из себя представляет реинжиниринг и какие инструментальные средства применяются при его проведении. Новизна данного вопроса предусматривает новый метод мышления и новый взгляд производителя на построение компании как на инженерную работу в её экономическом пространстве. Также рассматриваются проблемы внедрения и реализации бизнес-прочессов на предприятиях и критерии эффективности их реализации. При проведении успешного внедрения и использования реинжиниринга бизнес-проиессов можно получить ряд положительных эффектов: высокую продуктивность ведения бизнеса, повышение качества рабочей среды и внутренней управленческой среды, оптимизацию прочессов, включая возможный редизайн организационной структуры. Важная черта современной экономики - выход предприятий из кризиса, переход к новым технологиям и другие бизнес-проиессы требуют изменения и построения адекватной бизнес-структур.
\end{abstract}

Ключевые слова: реинжиниринг, бизнес-процессы, предприятие, внедрение, преимущество и недостатки.

ABDULAEVA AISHAT DAYTOVNA

a student of the "Dagestan state University», e-mail: adrianaivashkova@mail.ru

GASHIMOVA LEYLA GAMZABEKOVNA $\rho_{h}$. D., associate $P_{\text {rofessor of the Department "Management" FSBEI }}$ «Dagestan state University», e-mail: gashimova_leyla@mail.ru

\section{FEATURES OF REENGINEERING OF BUSINESS PROCESSES IN MODERN ENTERPRISES}

\begin{abstract}
This article discusses the aspects of reengineering business processes, the characteristics of reengineering, advantages and disadvantages of reengineering business processes and conditions for effective reengineering. The results of the review of this article allow us to understand what is reengineering, and what tools are used in its implementation.The novelty of this issue provides a new method of thinking and a new view of the manufacturer to build a company as an engineering work in its economic space. The problems of implementation and realization of business processes at the enterprises and criteria of efficiency of their realization are also considered. During the successful implementation and use of business process reengineering, a number of positive effects can be obtained: high business productivity, improving the quality of the working environment and internal management environment, process optimization, including a possible redesign of the organizational structure. An important feature of the modern economy - the exit of enterprises from the crisis, the transition to new technologies and other business processes require changes and the construction of adequate business structures.
\end{abstract}

Keywords: reengineering, business processes, enterprise, implementation, advantages and disadvantages. 
Актуальность темы исследования обоснована тем, что работа любой компании предполагает собой комплекс последовательных мероприятий (бизнес-процессов), которые направлены на определенную цель. В последнее время начали уделять большое внимание анализу бизнеспроцессов как предприятия в целом, так и отдельных проблемных участков [7].

О том, что российским компаниям надо «отлаживать бизнес-процессы», говорят менеджеры еще с конца 1990-х гг. Тогда появились книги американских авторов с незнакомой для бизнеса перестройки фразой «моделирование бизнес процессов» или «реинжиниринг бизнеспроцессов».

Что это такое, поняли быстро. Когда говорили о бизнес-процессах, речь шла о документации всех задач и мероприятий, которые в компании направлены на достижение главных целей. Например, магазин документирует процессы продажи товара, работы с покупателем, а также с поставщиками. Сеть салонов красоты будет описывать все мероприятия по оказанию услуг определенной группе клиентов.

Иногда менеджеры говорят об инжиниринге и реинжиниринге бизнес-процессов, в общемто, подразумевая одно и то же. Только в первом случае бизнес-процессы формируются в первый раз (engineering), а во втором - переделываются полностью (reengineering) [3].

Реинжиниринг бизнес-процессов - это кардинальная перестройка всех действий компании для увеличения прибыли и повышения конкурентоспособности предприятия. Под «предприятием» понимается любая компания, крупная или малый бизнес. Главное, чтобы там работало не меньше 10 человек [8]

Реинжиниринг является непростым и отчаянным шагом. В первую очередь, это объясняется глобальностью проводимых исследований, последующих изменений и отсутствием гарантии эффективного результата.

Часто специалист, реализующий проект, не способен соотнести риски, взвесить причины успехов и неудач, что обусловлено отсутствием интеллектуальных ресурсов для углубленного и критического анализа.

В процессе проведения реинжиниринга необходимо:

- Определить объект реинжиниринга.

- Учесть факторы успеха и неудачи проводимого проекта.

- Полностью погрузиться в анализ процессов в организации.

Реинжиниринг бизнес-процессов является настолько всесторонним действием, что он должен происходить на всех уровнях и включает в себя:

- изменение рабочих регламентов для сотрудников;

- перестроение протекающих внутри компании процессов;

- реформу структуры предприятия или конкретных отделов;

- переосмысление целей и миссии компании;

- изменение мышления сотрудников и руководства;

- автоматизацию через.

Максимально просто передать суть реинжиниринга можно в виде следующей схемы:

- постановка конкретных задач;

- анализ существующей модели работы;

- создание новой модели работы (идеальной);

- просчёт изменений, необходимых для перехода на новую модель;

- внесение этих изменений [3].

Преимуществом реинжиниринга бизнес-процессов является то, что происходит не просто улучшение деятельности компании, в некоторых подразделениях на $10-20 \%$, а улучшается состояние организации в целом.

Существует несколько наиболее актуальных методов совершенствования таких процессов:

- быстрое принятие решений;

- инжиниринг;

- реинжиниринг;

- перепроектирование процессов;

- бенчмаркинг. 
Преимущества и недостатки проведения реинжиниринга на предприятиях представлены в табл. [8].

\section{Преимущества и недостатки проведения реинжиниринга бизнес-процессов на предприятиях [2]}

\begin{tabular}{|l|l|}
\hline \multicolumn{1}{|c|}{ Преимущества } & \multicolumn{1}{|c|}{ Недостатки } \\
\hline Увеличивается скорость функционирования предприятия & Длительность проведения реинжиниринга \\
\hline Повышается конкурентоспособность компании & Большие затраты на проект \\
\hline Формируется высококвалифицированный персонал & $\begin{array}{l}\text { Из-за ущемления прав сотрудников напряженная пси- } \\
\text { хологическая обстановка }\end{array}$ \\
\hline $\begin{array}{l}\text { Переход к информационным технологиям, что упрощает } \\
\text { документооборот }\end{array}$ & $\begin{array}{l}\text { Высокий процент неудачного опыта при реализации } \\
\text { данного метода }\end{array}$ \\
\hline Снижаются издержки производства & $\begin{array}{l}\text { Повышается качество работы сотрудников и растет их мо- } \\
\text { тивация труда }\end{array}$ \\
\hline
\end{tabular}

Рассмотрим основные отличия реинжиниринга от совершенствования:

- Простое улучшение предполагает постепенное улучшение показателей. Реинжиниринг предполагает радикальный характер.

- Совершенствование осуществляется на основании уже действующих процессов. При реинжиниринге бизнес-процессы внедряются с «чистого листа».

- Простые улучшения реализуются на протяжении короткого периода, для полноценных изменений потребуется длительное время.

- При реинжиниринге новые процессы внедряются по направлению сверху вниз. При совершенствовании - наоборот.

- Улучшения характеризуются узким охватом, реинжиниринг - широким.

Реинжиниринг отличается повышенными рисками. Простые улучшения характеризуются умеренным риском [2].

Бизнес-процесс - это действия компании, направленные на создание продукта или услуги, удовлетворяющих потребности клиента. То есть главным является именно результат, который потребитель ожидает получить.

Это понятие самое важное, что должно усвоить руководство организации. Так как, не уловив сути бизнес-процессов, нельзя понять всю сущность реинжиниринга, что приводит впоследствии к неудачному опыту внедрения данной методологии.

Большинство компаний, проводя перестройку своего бизнеса, часто терпят неудачу.

Почему это происходит и какие ошибки совершают организации при проведении реинжиниринга, представлено далее:

1. Нежелание выходить из зоны комфорта и небольшие амбиции руководства.

2. Менеджеры среднего уровня не могут оценить весь процесс в целом.

3. Организация отказывается от кардинальной перестройки и только частично улучшает свою деятельность.

4. Недостаточное вложение инвестиций в проект реинжиниринга.

5. Ошибки руководства в управлении персоналом.

Ошибки, которые совершают компании, состоят в том, что они ориентируются не на процессы, а на отдельные структуры и задачи. Несомненно, по отдельности каждая задача и структура имеют свою ценность, но если потребитель не удовлетворён конечным результатом, то весь бизнес-процесс становится неэффективным [6].

Как уже упоминалось, реинжиниринг отличается высокими рисками, поэтому он практикуется не так часто. Перед проведением преобразований нужно проанализировать, действительно ли они так необходимы. Рассмотрим случаи, когда реинжиниринг необходим:

- Организации, проигрывающие конкурентную борьбу. Компания может утратить конкурентоспособность из-за относительно высоких цен на товар и низкого качества. Если фирма 
ничего не предпримет в данном случае, она будет разорена.

- Организации, в деятельности которой намечаются проблемы. К примеру, на рынке возник новый конкурент, изменилась ЦА, изменился экономический контекст.

- Компания, у которых нет никаких трудностей, которая желает захватить еще большую долю рынка. Как правило, это фирмы-лидеры, ведущие агрессивную маркетинговую политику.

Выделяют следующие условия эффективного реинжиниринга бизнес-процессов, которые подтверждены практикой:

- точность понимания задачи руководством компании;

- мотивация сотрудников компании, нацеленность на рост, расширение деятельности фирмы;

- эффективное управление компанией;

- научная методологическая основа при проведении реинжиниринга бизнес-процессов, использование опыта реорганизации предприятий [2].

В результате исследования данной статьи необходимо подчеркнуть, что главное избежать несистемный подход к преобразованию, неверную оценку деятельности компании, отсутствия последовательности и достаточных ресурсов - все это приводит к тому, что реинжиниринг не обеспечивает достижения поставленных целей. Компания тратит много средств на преобразование, однако новые бизнес-процессы внедрить не получается.

В результате реинжиниринга получается оптимизированный и эффективный бизнес. Негативным последствием которого могут являться полученные при объединении или удалении некоторых бизнес-процессов в угоду оптимизации массовые увольнения. Еще одна негативная сторона - это то, что реинжиниринг может и вовсе закончиться неудачей. Вследствие нарушения правил проведения, неоднозначной мотивации, проблем с бюджетом, проблем технологической поддержки.

Так, при проведении успешного внедрения и использования реинжиниринга бизнеспроцессов можно получать следующие положительные эффекты:

- высокая продуктивность ведения бизнеса;

- повышение качества рабочей среды и внутренней управленческой среды;

- оптимизация процессов, включая возможный редизайн организационной структуры [9].

Выводы по данной статье можно представить в следующем:

- важная черта современной экономики: выход предприятий из кризиса, переход к новым технологиям и другие бизнес-процессы требуют изменения и построения адекватной бизнесструктуры;

- реинжиниринг - это радикальное преобразование хозяйственной деятельности предприятия и структуры его управления, связанное с необходимостью совершенствования рабочего процесса с помощью современного подхода и технологий;

- как любой инструмент управления, реинжиниринг обладает как очевидными достоинствами, так и определенными недостатками, накладывающими ограничения на его использование;

- очень значимым фактором качественного реинжиниринга является переход предприятия на использование новых информационных технологий. Применение информационных технологий может отражаться как в принципиальных изменениях деятельности работников, так и в полной замене существующих бизнес-процессов;

- для эффективного внедрения и использования реинжиниринга бизнес-процессов необходимо иметь работников предприятия, являющихся высококвалифицированными экспертами на смежных участках бизнес-процесса, и сторонних консультантов - инженеров в области структурирования и моделирования бизнес- процессов;

- стоит учитывать ряд факторов и не жалеть времени, средств и сил его проведения. Данный метод должен быть обширным, и изменения, которые он повлечет, нужно вводить, подготовив перед этим персонал [1].

Таким образом, несмотря на современные недостатки использования на современном этапе отечественных предприятий, имеются некоторые недостатки. Реинжиниринг бизнес- 
процессов - важная черта современной экономики: выход предприятий из кризиса, переход к новым технологиям и другие бизнес-процессы требуют изменения и построения адекватной бизнес-структуры.

Литература

1. Геворгян, 3. В. Применение реинжиниринга бизнес-процессов // Экономические исследования и разработки : научно-исследовательский электронный журнал. - Нижний Новгород : НОО «Профессиональная наука», 2017. № 4. С.149-156.

2. Лубягина, Ю. В. Реинжиниринг бизнес-проиессов : содержание и проблемы реализации в современной экономике / Ю.В. Лубягина, М.Н. Попова, А.В. Дремина, Д.В. Бурнакова, М.Д. Прасолова // Экономика и менеджмент : сб. ст. по материалам ХІІІ междунар. науч.-практ. конф. № 1(13). — М. : Изд. «МЦНО», 2018. С. 63-67.

3. Как правильно использовать реинжиниринг бизнес-прочессов. - URL : https://www.comindware.com/ ru/blog-time-business-process-reengineering/ (дата обращения 01.04.2019).

4. Особенности реинжиниринга бизнес-процессов. - URL : https://assistentus.ru/vedenie-biznesa/ reinzhiniring-biznes-processov/ (дата обращзения 01.04.2019).

5. Реинжиниринг бизнес-прочессов // Бизнес. ру. 2018. - URL : https://www.business.ru/article/1239reinjiniring-biznes-protsessov-kkk (дата обращения 01.04.2019).

6. Реинжсинириг бизнес-прочессов предприятия : технология, понятие, методы и приниипь. - URL : https://kakzarabativat.ru/nachinayushhim-predprinimatelyam/reinzhiniring-biznes-processov/ (дата обращения 01.04.2019).

7. Селиверстов, А. С., Постнов, В. В., Уткин, Д. Ю., Семидотченко, А. Р., Николаева, К. А. Управление бизнес-процессами внутри предприятия [Текст] // Экономическая наука и практика : материаль VI междунар. науч. конф. (г. Чита, апрель 2018 г.). - Чита : Изд-во Молодой ученый, 2018. С. 46-48.

8. Хакимуллина, Я. Ф. Реинжиниринг бизнес-процессов предприятия / Хакимуллина, Ф. Я., А.Г. Файзуллина // Символ науки. 2016. №1-1. С. 214-216.

9. Шайдуллин, Р. Ф. Основные положения реинжиниринга // Современные научные исследования и инновации. 2014. № 10. Ч. 2. - URL : http://web.snauka.ru/issues/2014/10/39472 (дата обрашения 01.04.2019).

10.Кандауров, Н. Н. Инновационный менеджмент : курс лекиий. - М., 2006.

11. Тельнов, Ю. Ф. Технология проведения реинжиниринга бизнес-процессов : материаль семинара. M., 1996

12. Хаммер, М. Реинжиниринг корпорации : манифест революиии в бизнесе. - СПб., 1997.

13. Яблочников, Е. И. Реинжиниринг бизнес-процессов проектирования и производства : учеб. пособие. - СПб., 2010.

14. Андриенко, В. Н. Концептуальные основы управления инновационно-активным предприятием / B. H. Андриенко, А. И. Балдынюк // Вестник Астраханского государственного технического университета. Серия Экономика. - Астрахань : Астраханский государственный технический университет, 2017. № 1.

15. Баранов, В. В. Реинжиниринг бизнес-прочессов : этапы разработки и реализаџии / В. В. Баранов. URL : http://www.elitarium.ru/2012/11/14/reinzhiniring biznes processov jetapy razrabotki realizacii.html.

16. Молоткова, Н. В. Проектирование и реинжиниринг бизнес-прочессов в коммерции и бизнесинформатике : учеб. Пособие / Н. В. Молоткова, Д. Л. Хазанова, Т. И. Лапина. - Тамбов : ТГТУ, 2013.

17. Проказа, Т. В. Интеграџионные процессы в контексте инновационного развития предприятий / T. В. Проказа // Интегрированные основы инновационного и устойчивого развития экономики : сб. научных статей. -Пенза : Приволжский Дом знаний, 2013. С. 35-37.

18. Репин, В. В., Проиессный подход к управлению. Моделирование бизнес-проиессов / В. В. Репин, В. Г. Елиферов. - М. : Манн, Иванов и Фербер, 2013.

19. Хаммер, М. Реинжиниринг корпорачии. Манифест революичи в бизнесе / М. Хаммер, Д. Чампи. M., 2009 .

20.Hammer, M. \& Champy, J. Reengineering the Corporation. - Harper Business, 2001. P. 36-41.

21. URL : http://http//in-projects.ru/metody-proektirovaniya/inzhiniring-i-reinzhiniring-biznesproczessov.html.

22. URL : http://http//www.up-pro.ru/library/production_management/lean/otsech-lyshnee.html.

\section{References:}

1. Gevorgyan, Z. V. Primenenie reinzhiniringa biznes-processov // Ekonomicheskie issledovaniya i razrabotki : nauchno-issledovatel'skij elektronnyj zhurnal. — Nizhnij Novgorod : NOO «Professional'naya nauka», 2017. № 4. S.149-156.

2. Lubyagina, YU. V. Reinzhiniring biznes-processov : soderzhanie i problemy realizacii $v$ sovremennoj ekonomike / YU.V. Lubyagina, M.N. Popova, A.V. Dremina, D.V. Burnakova, M.D. Prasolova // Ekonomika $i$ menedzhment : sb. st. po materialam XIII mezhdunar. nauch.-prakt. konf. № 1(13). — M. : Izd. "MCNO», 2018. S. 63-67.

3. Kak pravil'no ispol'zovat' reinzhiniring biznes-processov. - URL : https://www.comindware.com/ru/blogtime-business-process-reengineering/(data obrashcheniya 01.04.2019).

4. Osobennosti reinzhiniringa biznes-processov. - URL : https://assistentus.ru/vedenie-biznesa/reinzhiniringbiznes-processov/ (data obrashcheniya 01.04.2019).

5. Reinzhiniring biznes-processov // Biznes. ru. 2018. - URL : https://www.business.ru/article/1239- 
АБДУЛАЕВА А.Д., ГАНИМОВА Л.Г.

ОСОБЕННОСТИ РЕИНЖИНИРИНГА БИЗНЕС-ПРОЦЕССОВ НА СОВРЕМЕННЫХ ПРЕДПРИЯТИЯХ

reinjiniring-biznes-protsessov-kkk (data obrashcheniya 01.04.2019).

6. Reinzhiniring biznes-processov predpriyatiya : tekhnologiya, ponyatie, metody i principy. - URL : https:// kakzarabativat.ru/nachinayushhim-predprinimatelyam/reinzhiniring-biznes-processov/ (data obrashcheniya 01.04.2019).

7. Seliverstov, A. S., Postnov, V. V., Utkin, D. YU., Semidotchenko, A. R., Nikolaeva, K. A. Upravlenie biznesprocessami vnutri predpriyatiya [Tekst] // Ekonomicheskaya nauka i praktika : materialy VI mezhdunar. nauch. konf. (g. CHita, aprel' 2018 g.). - CHita : Izd-vo Molodoj uchenyj, 2018. S. 46-48.

8. Hakimullina, YA. F. Reinzhiniring biznes-processov predpriyatiya / Hakimullina, F. YA., A.G. Fajzullina // Simvol nauki. 2016. №1-1. S. 214-216.

9. SHajdullin, R. F. Osnovnye polozheniya reinzhiniringa // Sovremennye nauchnye issledovaniya i innovacii. 2014. № 10. CH. 2. - URL : http://web.snauka.ru/issues/2014/10/39472 (data obrashcheniya 01.04.2019).

10. Kandaurov, N. N. Innovacionnyj menedzhment : kurs lekcij. - M., 2006.

11. Tel'nov, YU. F. Tekhnologiya provedeniya reinzhiniringa biznes-processov : materialy seminara. - M., 1996.

12. Hammer, M. Reinzhiniring korporacii : manifest revolyucii v biznese. - SPb., 1997.

13. YAblochnikov, E. I. Reinzhiniring biznes-processov proektirovaniya i proizvodstva : ucheb. posobie. SPb., 2010

14. Andrienko, V. N. Konceptual'nye osnovy upravleniya innovacionno-aktivnym predpriyatiem / V. N. Andrienko, A. I. Baldynyuk // Vestnik Astrahanskogo gosudarstvennogo tekhnicheskogo universiteta. Seriya Ekonomika. - Astrahan': Astrahanskij gosudarstvennyj tekhnicheskij universitet, 2017 . № 1.

15. Baranov, V. V. Reinzhiniring biznes-processov : etapy razrabotki $i$ realizacii / V. V. Baranov. - URL : http://www.elitarium.ru/2012/11/14/reinzhiniring biznes_processov_jetapy_razrabotki_realizacii.html.

16. Molotkova, N. V. Proektirovanie i reinzhiniring biznes-processov v kommercii i biznes-informatike : ucheb. Posobie / N. V. Molotkova, D. L. Hazanova, T. I. Lapina. — Tambov : TGTU, 2013.

17. Prokaza, T. V. Integracionnye processy v kontekste innovacionnogo razvitiya predpriyatij / T. V. Prokaza // Integrirovannye osnovy innovacionnogo i ustojchivogo razvitiya ekonomiki : sb. nauchnyh statej. -Penza : Privolzhskij Dom znanij, 2013. S. 35-37.

18. Repin, V. V., Processnyj podhod k upravleniyu. Modelirovanie biznes-processov / V. V. Repin, V. G. Eliferov. - M. : Mann, Ivanov i Ferber, 2013

19. Hammer, M. Reinzhiniring korporacii. Manifest revolyucii v biznese / M. Hammer, D. CHampi. - M. 2009.

20.Hammer, M. \& Champy, J. Reengineering the Corporation. - Harper Business, 2001. P. 36-41.

21. URL : http://http//in-projects.ru/metody-proektirovaniya/inzhiniring-i-reinzhiniring-biznesproczessov.html.

22. URL : http://http//www.up-pro.ru/library/production_management/lean/otsech-lyshnee.html. 